\title{
CULTURA DE SEGURANÇA DO PACIENTE EM TERAPIA INTENSIVA: REVISÃO INTEGRATIVA
}

\author{
PATIENT SAFETY CULTURE IN INTENSIVE CARE: \\ INTEGRATIVE REVIEW
}

\section{CULTURA DE LA SEGURIDAD DEL PACIENTE EN CUIDADOS INTENSIVOS: REVISIÓN INTEGRATIVA}

\author{
Nathália Dantas Farias Kruschewsky ${ }^{1}$ \\ Kátia Santana Freitas ${ }^{2}$ \\ Aloísio Machado da Silva Filho ${ }^{3}$
}

\begin{abstract}
Como citar este artigo: Kruschewsky NDF, Freitas KS, Silva Filho AM. Cultura de segurança do paciente em terapia intensiva: revisão integrativa. Rev baiana enferm. 2021;35:e37164.

Objetivo: identificar o conhecimento produzido na literatura sobre a cultura de segurança do paciente em cuidados intensivos. Método: trata-se de uma revisão integrativa fundamentada no referencial teórico de Whittemore e Knaf, realizada nos portais PubMed, Biblioteca Virtual da Saúde (BVS) e Scientific Electronic Library Online (SciELO), mediante cruzamento dos descritores "organizational culture", "patient safety", e "intensive care units", por meio do operador booleano "AND", totalizando 22 publicações. Resultados: foram identificadas três categorias de evidências: instrumentos para avaliação da cultura de segurança do paciente, fortalezas e fragilidades da cultura de segurança do paciente em terapia intensiva, cultura de segurança do paciente em terapia intensiva e fatores associados. Conclusão: as publicações demonstraram o quanto é difícil construir uma cultura de segurança local, já que nenhuma apresentou uma cultura de segurança do paciente positiva. Entretanto, foram demonstrados fatores associados à cultura de segurança, nos quais é possível intervir para melhor efetivá-la.
\end{abstract}

Descritores: Unidades de Terapia Intensiva. Segurança do Paciente. Cultura Organizacional.

Objective: to identify the knowledge produced in the literature on patient safety culture in intensive care. Method: this is an integrative review based on the theoretical framework of Whittemore and Knaf, carried out at the portals PubMed, Virtual Health Library (VHL) and Scientific Electronic Library Online (SciELO), through the crossing of the descriptors "organizational culture", "patient safety", and "intensive care units", through the Boolean operator "AND", totaling 22 publications. Results: three categories of evidence were identified: instruments for assessing the patient safety culture, strengths and weaknesses of the patient safety culture in intensive care, patient safety culture in intensive care and associated factors. Conclusion: the publications demonstrated the difficulty to build a local safety culture, since none presented a positive patient safety culture. However, factors associated with the safety culture were demonstrated, in which it is possible to intervene for its better implementation.

Descriptors: Intensive Care Units. Patient Safety. Organizational Culture.

Objetivo: identificar los conocimientos producidos en la literatura sobre la cultura de la seguridad del paciente en cuidados intensivos. Método: se trata de una revisión integrativa basada en el marco teórico de Whittemore y Knaf, llevada a cabo en los portales PubMed, Biblioteca Virtual en Salud (BVS) y Scientific Electronic Library Online

\footnotetext{
Enfermeira. Especialista em Enfermagem Intensiva. Mestre em Enfermagem. Enfermeira do Hospital Cardio Pulmonar. Salvador, Bahia, Brasil. nathaliadfk@yahoo.com.br. https://orcid.org/0000-0002-2195-2209.

2 Enfermeira. Doutora em Enfermagem. Professora Adjunta da Universidade Estadual de Feira de Santana. Feira de Santana, Bahia, Brasil. https://orcid.org/0000-0002$0491-6759$.

Bacharel em Estatística. Doutor em Modelagem Computacional e Tecnologia Industrial. Professor Titular da Universidade Estadual de Feira de Santana. Feira de Santana, Bahia, Brasil. https://orcid.org/0000-000 I-8250- I 527.
} 
(SciELO), a través del cruce de los descriptores "organizational culture", "patient safety", y "intensive care units", a través del operador booleano "AND", totalizando 22 publicaciones. Resultados: se identificaron tres categorías de evidencia: instrumentos para evaluar la cultura de la seguridad del paciente, fortalezas y debilidades de la cultura de la seguridad de los pacientes en cuidados intensivos, cultura de la seguridad del paciente en cuidados intensivos y factores asociados. Conclusión: las publicaciones demostraron lo difícil que es construir una cultura de seguridad local, ya que ninguna presentaba una cultura positiva de seguridad del paciente. Sin embargo, se demostraron factores asociados con la cultura de la seguridad, en los que es posible intervenir para mejorar la efectuar.

Descriptores: Unidades de Cuidados Intensivos. Seguridad del Paciente. Cultura Organizacional.

\section{Introdução}

A prestação do cuidado em saúde traz melhorias significativas aos seus usuários, porém o risco de danos em sua execução é reconhecido, o que pode expor os pacientes a consequências graves e muitas vezes irreversíveis, além de gerar custos físicos, sociais e econômicos significativos $^{(1)}$. Por esse motivo, a abordagem da segurança do paciente no ambiente hospitalar, admitida como uma dimensão da qualidade em saúde, vem adquirindo força nos últimos anos ${ }^{(2)}$.

A segurança do paciente é conceituada pela Organização Mundial da Saúde (OMS) como a redução, a um mínimo aceitável, do risco de dano desnecessário associado ao cuidado de saúde ${ }^{(3)}$. Desse modo, ainda que os riscos existam e sejam inerentes à prática assistencial, ações de melhoria devem ser implementadas constantemente, a fim de reduzir a probabilidade de que pacientes sejam vítimas de danos associados à prestação da assistência em saúde.

Dez áreas temáticas que afetam a segurança do paciente foram apresentadas pela OMS. A cultura de segurança do paciente está descrita nessa composição, sendo apontada como um dos fatores organizacionais e de gestão que exercem influência nos cuidados de saúde ${ }^{(4)}$.

No Brasil, em 2013, foi criado o Programa Nacional de Segurança do Paciente (PNSP). Dentre as diversas estratégias de implementação do PNSP, ressalta-se, em seu art. 5o, a promoção da cultura de segurança ${ }^{(5)}$. Definida como o produto de valores individuais e coletivos, atitudes, percepções, competências e padrões de comportamento que determinam o compromisso, o estilo e a proficiência de uma organização de saúde na gestão da segurança do paciente, seu desenvolvimento é essencial para a prestação de uma assistência à saúde segura e de qualidade ${ }^{(6)}$.

Para transformar e consolidar a cultura de segurança de um serviço, o primeiro passo é conhecê-la. Concluída essa avaliação, é possível identificar as áreas que necessitam de melhorias, viabilizando intervenções mais efetivas, bem como os aspectos positivos, para assim fortalecê-los ${ }^{(7)}$.

Diante disso, vários instrumentos de pesquisa foram desenvolvidos para medir cultura de segurança no contexto hospitalar. Ressaltam-se o Safety Attitudes Questionnaire (SAQ) e o Hospital Survey on Patient Safety Culture (HSOPSC). Ambos são bastante utilizados mundialmente e foram traduzidos e validados para a realidade brasileira ${ }^{(8)}$.

A implementação e avaliação da cultura de segurança torna-se necessária nos mais diversos ambientes de prestação de cuidados à saúde, em especial nas Unidades de Terapia Intensiva (UTI). Esta constitui-se em uma área crítica, destinada à internação de pacientes graves, expostos a importantes fatores de risco associados à ocorrência de eventos adversos ${ }^{(9)}$. Dados da Agência Nacional de Vigilância Sanitária (Anvisa) demonstram que as UTIs são a segunda unidade hospitalar com mais notificações de incidentes relacionados à assistência à saúde ${ }^{(10)}$.

Perante este cenário, gestores hospitalares e das UTIs devem garantir a segurança e a proteção de pacientes, bem como devem ser monitorados e mantidos registros de avaliações do padrão de funcionamento global da UTI, assim como de eventos que possam indicar necessidade de melhoria da qualidade da assistência ${ }^{(9)}$. 
A magnitude dos eventos adversos em UTIs e a indispensabilidade da realização de avaliações da cultura de segurança, com seu consequente estabelecimento, no âmbito dos cuidados críticos, uma vez que danos na saúde poderão ser evitados, consolidam o entendimento de que a cultura de segurança entre os funcionários deve ser buscada.

Acredita-se que as buscas desta pesquisa permitirão explorar o panorama mundial relacionado à temática, estimulando diversas instituições de saúde a conhecerem suas realidades, com vistas à implementação de aperfeiçoamentos necessários, fortalecendo a prestação de cuidados seguros e de qualidade.

O objetivo deste estudo é identificar o conhecimento produzido na literatura nacional e internacional sobre a cultura de segurança do paciente em cuidados intensivos.

\section{Método}

Trata-se de uma revisão integrativa realizada em julho de 2019, fundamentada no referencial teórico de Whittemore e Knaf ${ }^{(11)}$. Foi desenvolvida nas seguintes etapas: identificação do tema e seleção da questão de pesquisa, estabelecimento dos critérios de inclusão e exclusão, identificação dos estudos selecionados, categorização dos estudos, análise e interpretação dos resultados, síntese do conhecimento.
Para seleção das publicações, realizou-se cruzamento dos Descritores em Ciências da Saúde (DeCS) e do Medical Subject Headings (MeSH), "organizational culture", "patient safety", e "intensive care units", por meio do operador booleano " $A N D$ " nos portais PubMed, Biblioteca Virtual da Saúde (BVS) e Scientific Electronic Library Online (SciELO).

A investigação foi conduzida pela seguinte questão: Qual o conhecimento produzido na literatura nacional e internacional sobre a cultura de segurança do paciente em unidades de terapia intensiva?

Foram incluídos artigos originais que tratavam da cultura de segurança do paciente como tema central, desenvolvidos em UTIs, publicados nos últimos dez anos (2009 a 2019), nos idiomas português, inglês e espanhol. Excluídos artigos de revisão, editoriais, teses, dissertações, textos que não estivessem disponíveis na íntegra e fora da temporalidade estabelecida. Os artigos repetidos em mais de uma base de dados foram incluídos uma única vez.

As publicações foram inicialmente selecionadas com base na leitura do título e do resumo, para identificar se faziam parte da temática de investigação e estabelecer quais textos seriam lidos na íntegra.

Após a leitura dos estudos selecionados, aqueles que preencheram os critérios de inclusão fizeram parte da revisão, totalizando 22 estudos, conforme Fluxograma 1.

Fluxograma 1 - Seleção das publicações

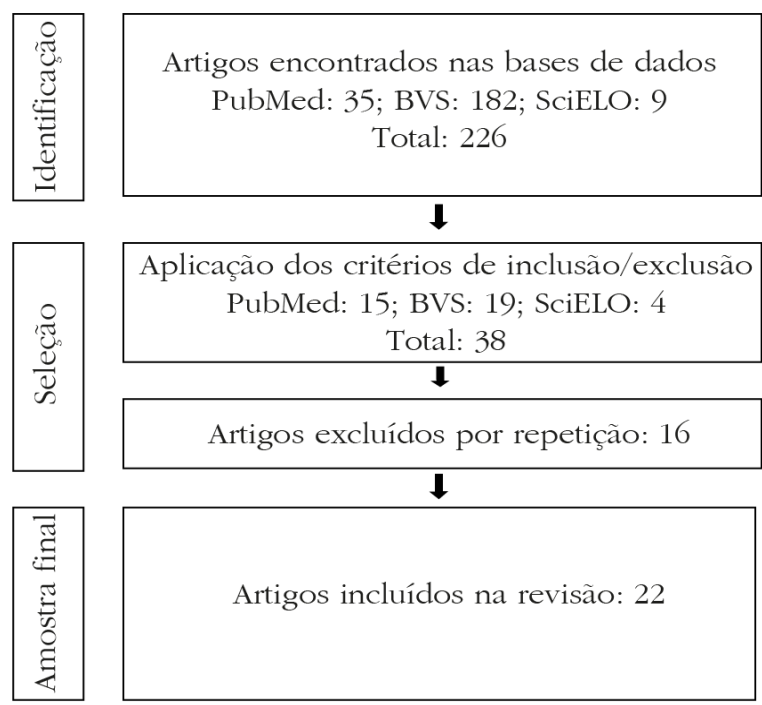


Após leitura exploratória das publicações encontradas, foi elaborado um quadro sinóptico, a fim de sintetizar as principais informações. Assim, tornou-se possível identificar título, objetivo, instrumento utilizado para avaliação da cultura de segurança e principais resultados.

Para análise, interpretação dos dados e síntese do conhecimento, foram evidenciadas as principais similaridades encontradas nos estudos, que foram sintetizadas e agrupadas, emergindo três categorias de evidências para análise.

\section{Resultados}

A análise das 22 publicações encontradas revelou que 8 (36,3\%) foram realizadas nos Estados Unidos (EUA), 7 (31,8\%) no Brasil, 2 (9,1\%) na Noruega e no Irã, e $1(4,5 \%)$ na Austrália, Suécia e China. As produções brasileiras foram desenvolvidas apenas nas regiões Sul e Sudeste do país. O inglês foi o idioma de publicação de 15 $(68,2 \%)$ estudos e 7 (31,8\%) foram publicados em português.

Quanto à distribuição por temporalidade, observou-se número maior de pesquisas nos anos de 2014, 2016 e 2017, sendo contabilizadas 4 (18,2\%) em cada um desses anos, seguidos dos anos de 2013, com 3 (13,6\%) publicações, 2012 e 2015, com 2 (9,1\%), e 2010, 2018 e 2019, cada um com 1 (4,5\%) publicação. Não foram encontrados estudos publicados nos anos de 2009 e 2011. No que concerne às pesquisas desenvolvidas no Brasil, constatou-se a presença dessas a partir do ano de 2013, época da criação do PNSP.

Revelou-se um número expressivo de produções em periódicos da área de enfermagem, perfazendo um total de 10 (45,5\%) trabalhos, o que demonstra a sensibilização e o interesse dessa categoria em relação à temática em análise.

Os instrumentos utilizados para a coleta dos dados referente à cultura de segurança do paciente foram o HSOPSC, em 10 (45,5\%) trabalhos e o SAQ, em 7 (31,8\%) investigações. Recorreram a esses 2 questionários, 4 (18,1\%) avaliações. Apenas 1 (4,5\%) pesquisa aplicou entrevistas semiestruturadas. Para análise dos dados, 21 (95,5\%) artigos empregaram metodologia de abordagem quantitativa e apenas 1 (4,5\%) abordou os dados qualitativamente.

Para facilitar a compreensão das informações, foi elaborado um quadro sinóptico (Quadro 1) com o resumo dos dados oriundos desta revisão, conforme apresentado a seguir.

Quadro 1 - Distribuição das publicações selecionadas de acordo com título, objetivo(s), instrumento utilizado para avaliação e principais resultados

(continua)

\begin{tabular}{|c|c|c|c|c|}
\hline No & Título & Objetivo(s) & $\begin{array}{c}\text { Instrumento } \\
\text { para avaliação }\end{array}$ & Principais resultados \\
\hline 1 & $\begin{array}{l}\text { Burnout in the NICU } \\
\text { setting and its relation } \\
\text { to safety culture }{ }^{(12)} \text {. }\end{array}$ & $\begin{array}{l}\text { Examinar as relações entre } \\
\text { o burnout do cuidador e } \\
\text { a cultura de segurança do } \\
\text { paciente. }\end{array}$ & $\begin{array}{l}\text { Safety Attitudes } \\
\text { Questionnaire }\end{array}$ & $\begin{array}{l}\text { Associação significativa entre } \\
\text { altos escores de burnout e } \\
\text { baixos escores de cultura de } \\
\text { segurança. }\end{array}$ \\
\hline 2 & $\begin{array}{l}\text { Changes in patient } \\
\text { safety culture after } \\
\text { restructuring of } \\
\text { intensive care units: } \\
\text { Two cross-sectional } \\
\text { studies }^{(13)} \text {. }\end{array}$ & $\begin{array}{l}\text { Comparar as mudanças na } \\
\text { percepção dos enfermeiros } \\
\text { sobre a cultura de } \\
\text { segurança do paciente } \\
\text { em unidades de terapia } \\
\text { intensiva reestruturadas e } \\
\text { não reestruturadas. }\end{array}$ & $\begin{array}{l}\text { Hospital Survey } \\
\text { on Patient Safety } \\
\text { Culture }\end{array}$ & $\begin{array}{l}\text { A reestruturação das unidades } \\
\text { foi negativamente associada } \\
\text { com a mudança na cultura de } \\
\text { segurança. }\end{array}$ \\
\hline 3 & $\begin{array}{l}\text { CNE article: safety } \\
\text { culture in Australian } \\
\text { intensive care } \\
\text { units: establishing a } \\
\text { baseline for quality } \\
\text { improvement }^{(14)} \text {. }\end{array}$ & $\begin{array}{l}\text { Estabelecer uma } \\
\text { compreensão básica da } \\
\text { cultura de segurança } \\
\text { em unidades de terapia } \\
\text { intensiva australianas. }\end{array}$ & $\begin{array}{l}\text { Safety Attitudes } \\
\text { Questionnaire }\end{array}$ & $\begin{array}{l}\text { Baixa proporção de respostas } \\
\text { positivas variando de } 18,8 \% \text { a } \\
48,1 \% \text {. A categoria profissional } \\
\text { foi associada a algumas } \\
\text { dimensões. }\end{array}$ \\
\hline
\end{tabular}


Quadro 1 - Distribuição das publicações selecionadas de acordo com título, objetivo(s), instrumento utilizado para avaliação e principais resultados

(continuação)

\begin{tabular}{|c|c|c|c|c|}
\hline № & Título & Objetivo(s) & $\begin{array}{c}\text { Instrumento } \\
\text { para avaliação }\end{array}$ & Principais resultados \\
\hline 4 & $\begin{array}{l}\text { Comparing NICU } \\
\text { teamwork and safety } \\
\text { climate across two } \\
\text { commonly used } \\
\text { survey instruments }{ }^{(15)} \text {. }\end{array}$ & $\begin{array}{l}\text { Avaliar a variação no } \\
\text { clima de segurança e } \\
\text { trabalho em equipe no } \\
\text { ambiente de UTI neonatal } \\
\text { e comparar a medição } \\
\text { de escalas de cultura de } \\
\text { segurança usando dois } \\
\text { instrumentos diferentes. }\end{array}$ & $\begin{array}{l}\text { Safety Attitudes } \\
\text { Questionnaire e } \\
\text { Hospital Survey } \\
\text { on Patient Safety } \\
\text { Culture }\end{array}$ & $\begin{array}{l}\text { Sexo, categoria profissional, } \\
\text { tempo de experiência } \\
\text { profissional e porte da UTI } \\
\text { foram associados a cultura de } \\
\text { segurança. }\end{array}$ \\
\hline 5 & $\begin{array}{l}\text { Cultura e clima } \\
\text { organizacional } \\
\text { para segurança do } \\
\text { paciente em Unidades } \\
\text { de Terapia Intensiva }{ }^{(8)} \text {. }\end{array}$ & $\begin{array}{l}\text { Avaliar a percepção dos } \\
\text { profissionais de saúde } \\
\text { sobre o clima e a cultura } \\
\text { de segurança do paciente } \\
\text { em Unidades de Terapia } \\
\text { Intensiva e a relação } \\
\text { entre os instrumentos } \\
\text { Hospital Survey on Patient } \\
\text { Safety Culture e o Safety } \\
\text { Attitudes Questionnaire. }\end{array}$ & $\begin{array}{l}\text { Safety Attitudes } \\
\text { Questionnaire e } \\
\text { Hospital Survey } \\
\text { on Patient Safety } \\
\text { Culture }\end{array}$ & $\begin{array}{l}\text { As escalas apresentaram boa } \\
\text { confiabilidade. A correlação } \\
\text { entre as escalas foi de força } \\
\text { moderada }(r=0,66) \text {. }\end{array}$ \\
\hline 6 & $\begin{array}{l}\text { Evaluation of the } \\
\text { association between } \\
\text { Hospital Survey on } \\
\text { Patient Safety Culture } \\
\text { (HSOPS) measures } \\
\text { and catheter- } \\
\text { associated infections: } \\
\text { results of two national } \\
\text { collaboratives }\end{array}$ & $\begin{array}{l}\text { Examinar a associação } \\
\text { entre os resultados das } \\
\text { unidades hospitalares } \\
\text { para o Hospital Survey } \\
\text { on Patient Safety Culture } \\
\text { e as taxas de infecção } \\
\text { associadas ao cateter. }\end{array}$ & $\begin{array}{l}\text { Hospital Survey } \\
\text { on Patient Safety } \\
\text { Culture }\end{array}$ & $\begin{array}{l}\text { Não foram encontradas } \\
\text { associações entre os } \\
\text { resultados do Hospital Survey } \\
\text { on Patient Safety Culture e as } \\
\text { taxas de infecção relacionadas } \\
\text { a cateter. }\end{array}$ \\
\hline 7 & $\begin{array}{l}\text { Avaliação da cultura } \\
\text { de segurança do } \\
\text { paciente em terapia } \\
\text { intensiva neonatal }^{(17)} \text {. }\end{array}$ & $\begin{array}{l}\text { Analisar a cultura de } \\
\text { segurança do paciente na } \\
\text { perspectiva das equipes } \\
\text { de enfermagem e médica. }\end{array}$ & $\begin{array}{l}\text { Hospital Survey } \\
\text { on Patient Safety } \\
\text { Culture }\end{array}$ & $\begin{array}{l}\text { 43\% de respostas positivas } \\
\text { em todo o questionário e } \\
\text { nenhuma dimensão pontuou } \\
\text { acima de } 75 \% \text {. }\end{array}$ \\
\hline 8 & $\begin{array}{l}\text { Exposure to } \\
\text { Leadership } \\
\text { WalkRounds in } \\
\text { neonatal intensive } \\
\text { care units is } \\
\text { associated with a } \\
\text { better patient safety } \\
\text { culture and less } \\
\text { caregiver burnout }\end{array}$ & $\begin{array}{l}\text { Avaliar a associação entre } \\
\text { feedback das rondas de } \\
\text { segurança, cultura de } \\
\text { segurança do paciente e } \\
\text { burnout do cuidador. }\end{array}$ & $\begin{array}{l}\text { Safety Attitudes } \\
\text { Questionnaire e } \\
\text { Hospital Survey } \\
\text { on Patient Safety } \\
\text { Culture }\end{array}$ & $\begin{array}{l}\text { Maior realização de feedback } \\
\text { foi associado a melhores } \\
\text { resultados de cultura de } \\
\text { segurança. }\end{array}$ \\
\hline 9 & $\begin{array}{l}\text { Intensive care unit } \\
\text { safety culture and } \\
\text { outcomes: a US } \\
\text { multicenter study }{ }^{(19)} \text {. }\end{array}$ & $\begin{array}{l}\text { Determinar se a cultura } \\
\text { de segurança da UTI } \\
\text { está independentemente } \\
\text { associada à mortalidade } \\
\text { hospitalar do paciente e } \\
\text { ao tempo de internação. }\end{array}$ & $\begin{array}{l}\text { Safety Attitudes } \\
\text { Questionnaire }\end{array}$ & $\begin{array}{l}\text { Queda na pontuação para } \\
\text { percepções de gestão } \\
\text { aumentou a chance de morte. } \\
\text { Redução na pontuação do } \\
\text { clima de segurança aumentou } \\
\text { o tempo de permanência. }\end{array}$ \\
\hline 10 & $\begin{array}{l}\text { Neonatal intensive } \\
\text { care unit safety } \\
\text { culture varies } \\
\text { widely }^{(20)} \text {. }\end{array}$ & $\begin{array}{l}\text { Descrever as avaliações } \\
\text { da cultura de segurança, } \\
\text { explorar a variabilidade } \\
\text { dentro e entre Unidades } \\
\text { de Terapia Intensiva } \\
\text { Neonatais nos domínios } \\
\text { de cultura de segurança } \\
\text { e teste de associação } \\
\text { com as características do } \\
\text { profissional. }\end{array}$ & $\begin{array}{l}\text { Safety Attitudes } \\
\text { Questionnaire }\end{array}$ & $\begin{array}{l}\text { Os escores dos médicos foram } \\
\text { maiores do que da equipe de } \\
\text { enfermagem. }\end{array}$ \\
\hline
\end{tabular}


Quadro 1 - Distribuição das publicações selecionadas de acordo com título, objetivo(s), instrumento utilizado para avaliação e principais resultados

(continuação)

\begin{tabular}{|c|c|c|c|c|}
\hline No & Título & Objetivo(s) & $\begin{array}{c}\text { Instrumento } \\
\text { para avaliação }\end{array}$ & Principais resultados \\
\hline 11 & $\begin{array}{l}\text { On the CUSP: Stop } \\
\text { BSI: evaluating the } \\
\text { relationship between } \\
\text { central line-associated } \\
\text { bloodstream infection } \\
\text { rate and patient } \\
\text { safety climate } \\
\text { profile }^{(21)} \text {. }\end{array}$ & $\begin{array}{l}\text { Medir o clima de } \\
\text { segurança para investigar } \\
\text { a relação entre perfis } \\
\text { climáticos de segurança } \\
\text { do paciente na Unidades } \\
\text { de Terapia Intensiva } \\
\text { e taxas de infecção } \\
\text { de corrente sanguínea } \\
\text { associada a acesso central. }\end{array}$ & $\begin{array}{l}\text { Hospital Survey } \\
\text { on Patient Safety } \\
\text { Culture }\end{array}$ & $\begin{array}{l}\text { Unidades de Terapia } \\
\text { Intensiva com climas } \\
\text { conflitantes tiveram um risco } \\
\text { significativamente maior } \\
\text { de infecção de corrente } \\
\text { sanguínea associada a acesso } \\
\text { central em comparação com } \\
\text { as Unidades de Terapia } \\
\text { Intensiva com clima de } \\
\text { liderança generativa. }\end{array}$ \\
\hline 12 & $\begin{array}{l}\text { Cultura de segurança } \\
\text { do paciente em } \\
\text { unidades de terapia } \\
\text { intensiva neonatal: } \\
\text { perspectivas } \\
\text { da equipe de } \\
\text { enfermagem e } \\
\text { médica }^{(22)} \text {. }\end{array}$ & $\begin{array}{l}\text { Verificar a avaliação da } \\
\text { cultura de segurança do } \\
\text { paciente de acordo com } \\
\text { a função e o tempo de } \\
\text { experiência das equipes } \\
\text { de enfermagem e médica. }\end{array}$ & $\begin{array}{l}\text { Hospital Survey } \\
\text { on Patient Safety } \\
\text { Culture }\end{array}$ & $\begin{array}{l}\text { O escore geral de respostas } \\
\text { positivas foi } 43 \% \text {. As respostas } \\
\text { diferiram de acordo com a } \\
\text { categoria profissional, tempo } \\
\text { de trabalho no hospital, } \\
\text { tempo de trabalho na } \\
\text { unidade, tempo de trabalho } \\
\text { na profissão. }\end{array}$ \\
\hline 13 & $\begin{array}{l}\text { Cultura de segurança } \\
\text { do paciente em } \\
\text { unidade de terapia } \\
\text { intensiva: perspectiva } \\
\text { da equipe de } \\
\text { enfermagem }^{(23)} \text {. }\end{array}$ & $\begin{array}{l}\text { Identificar e comparar as } \\
\text { dimensões da cultura de } \\
\text { segurança do paciente na } \\
\text { perspectiva dos profissionais } \\
\text { de enfermagem de duas } \\
\text { Unidades de Terapia } \\
\text { Intensiva. }\end{array}$ & $\begin{array}{l}\text { Hospital Survey } \\
\text { on Patient Safety } \\
\text { Culture }\end{array}$ & $\begin{array}{l}\text { As dimensões com maior } \\
\text { avaliação positiva foram } \\
\text { trabalho em equipe nas } \\
\text { unidades, expectativas e } \\
\text { ações para promoção da } \\
\text { segurança do supervisor e } \\
\text { aprendizado organizacional. }\end{array}$ \\
\hline 14 & $\begin{array}{l}\text { Patient Safety } \\
\text { Culture in Intensive } \\
\text { Care Units from the } \\
\text { Perspective of Nurses: } \\
\text { A Cross-Sectional } \\
\text { Study }{ }^{(24)} \text {. }\end{array}$ & $\begin{array}{l}\text { Pesquisar a cultura de } \\
\text { segurança do paciente na } \\
\text { perspectiva de enfermeiros } \\
\text { em Unidades de Terapia } \\
\text { Intensiva. }\end{array}$ & $\begin{array}{l}\text { Hospital Survey } \\
\text { on Patient Safety } \\
\text { Culture }\end{array}$ & $\begin{array}{l}\text { A pontuação geral de } \\
\text { respostas positivas foi de } \\
57,7 \% \text {, o que indicou que o } \\
\text { nível de cultura de segurança } \\
\text { era médio. }\end{array}$ \\
\hline 15 & $\begin{array}{l}\text { Cultura de segurança } \\
\text { do paciente em } \\
\text { terapia intensiva: } \\
\text { recomendações da } \\
\text { enfermagem }^{(25)} \text {. }\end{array}$ & $\begin{array}{l}\text { Sistematizar as } \\
\text { recomendações dos } \\
\text { profissionais de } \\
\text { enfermagem acerca da } \\
\text { segurança do paciente. }\end{array}$ & $\begin{array}{l}\text { Hospital Survey } \\
\text { on Patient Safety } \\
\text { Culture }\end{array}$ & $\begin{array}{l}\text { Maior número de } \\
\text { recomendações para as } \\
\text { dimensões aprendizado } \\
\text { organizacional e melhoria } \\
\text { contínua, pessoal, e } \\
\text { percepção geral de segurança } \\
\text { do paciente. }\end{array}$ \\
\hline 16 & $\begin{array}{l}\text { Cultura de segurança } \\
\text { em unidades de } \\
\text { terapia intensiva } \\
\end{array}$ & $\begin{array}{l}\text { Avaliar a cultura de } \\
\text { segurança do paciente na } \\
\text { perspectiva dos profissionais } \\
\text { da equipe de saúde. }\end{array}$ & $\begin{array}{l}\text { Safety Attitudes } \\
\text { Questionnaire }\end{array}$ & $\begin{array}{l}\text { A pontuação média obtida } \\
\text { pelo Safety Attitudes } \\
\text { Questionnaire foi } 62,38 \\
\text { pontos. }\end{array}$ \\
\hline 17 & $\begin{array}{l}\text { Systematic simulation- } \\
\text { based team training } \\
\text { in a Swedish } \\
\text { intensive care unit: } \\
\text { a diverse response } \\
\text { among critical care } \\
\text { professions }{ }^{(27)} \text {. }\end{array}$ & $\begin{array}{l}\text { Examinar a relação entre } \\
\text { o treinamento em equipe } \\
\text { baseado em simulação e } \\
\text { segurança. }\end{array}$ & $\begin{array}{l}\text { Safety Attitudes } \\
\text { Questionnaire }\end{array}$ & $\begin{array}{l}\text { A percepção da equipe } \\
\text { de enfermagem sobre os } \\
\text { fatores do Safety Attitudes } \\
\text { Questionnaire foi mais } \\
\text { positiva após o projeto. }\end{array}$ \\
\hline 18 & $\begin{array}{l}\text { The association } \\
\text { between patient } \\
\text { safety culture and } \\
\text { burnout and sense } \\
\text { of coherence: } A \\
\text { cross-sectional study } \\
\text { in restructured and } \\
\text { not restructured } \\
\text { intensive care units } \\
\text { int) }^{(28)}\end{array}$ & $\begin{array}{l}\text { Estudar as associações } \\
\text { entre a percepção dos } \\
\text { enfermeiros sobre a } \\
\text { cultura de segurança do } \\
\text { paciente, burnout e senso } \\
\text { de coerência. }\end{array}$ & $\begin{array}{l}\text { Hospital Survey } \\
\text { on Patient Safety } \\
\text { Culture }\end{array}$ & $\begin{array}{l}\text { Uma cultura de segurança } \\
\text { positiva foi estatisticamente } \\
\text { associada a uma pontuação } \\
\text { baixa para burnout e um forte } \\
\text { senso de coerência. }\end{array}$ \\
\hline
\end{tabular}


Quadro 1 - Distribuição das publicações selecionadas de acordo com título, objetivo(s), instrumento utilizado para avaliação e principais resultados

\begin{tabular}{|c|c|c|c|c|}
\hline № & Título & Objetivo(s) & $\begin{array}{c}\text { Instrumento } \\
\text { para avaliação }\end{array}$ & Principais resultados \\
\hline 19 & $\begin{array}{l}\text { The Effect of a Freely } \\
\text { Available Flipped } \\
\text { Classroom Course } \\
\text { on Health Care } \\
\text { Worker Patient Safety } \\
\text { Culture: A Prospective } \\
\text { Controlled Study }{ }^{(29)} \text {. }\end{array}$ & $\begin{array}{l}\text { Avaliar o impacto de um } \\
\text { curso padronizado de } \\
\text { segurança do paciente na } \\
\text { cultura de segurança do } \\
\text { paciente. }\end{array}$ & $\begin{array}{l}\text { Hospital Survey } \\
\text { on Patient Safety } \\
\text { Culture }\end{array}$ & $\begin{array}{l}\text { Após o curso de segurança } \\
\text { houve melhora significativa } \\
\text { nas respostas para trabalho } \\
\text { em equipe dentro das } \\
\text { unidades hospitalares e apoio } \\
\text { da gestão hospitalar para a } \\
\text { segurança do paciente. }\end{array}$ \\
\hline 20 & $\begin{array}{l}\text { The Safety Attitudes } \\
\text { Questionnaire as a } \\
\text { tool for benchmarking } \\
\text { safety culture in the } \\
\text { NICU }^{30)} \text {. }\end{array}$ & $\begin{array}{l}\text { Determinar se as dimensões } \\
\text { da cultura de segurança } \\
\text { fornecem resultados } \\
\text { consistentes quando } \\
\text { usadas como medida de } \\
\text { desempenho da Unidade } \\
\text { de Terapia Intensiva. }\end{array}$ & $\begin{array}{l}\text { Safety Attitudes } \\
\text { Questionnaire }\end{array}$ & $\begin{array}{l}\text { O Safety Attitudes } \\
\text { Questionnaire pode ser uma } \\
\text { ferramenta útil para avaliações } \\
\text { de desempenho comparativo } \\
\text { entre Unidades de Terapia } \\
\text { Intensiva Neonatais. }\end{array}$ \\
\hline 21 & $\begin{array}{l}\text { The effect of nurse } \\
\text { empowerment } \\
\text { educational program } \\
\text { on patient safety } \\
\text { culture: a randomized } \\
\text { controlled triat }{ }^{31)} \text {. }\end{array}$ & $\begin{array}{l}\text { Determinar o efeito } \\
\text { da capacitação de } \\
\text { enfermeiros e supervisores } \\
\text { através de um programa } \\
\text { educacional. }\end{array}$ & $\begin{array}{l}\text { Hospital Survey } \\
\text { on Patient Safety } \\
\text { Culture }\end{array}$ & $\begin{array}{l}\text { No grupo experimental, } \\
\text { os escores foram } \\
\text { significativamente maiores do } \\
\text { que os do grupo controle. }\end{array}$ \\
\hline 22 & $\begin{array}{l}\text { Cultura de segurança } \\
\text { em unidades de terapia } \\
\text { intensiva: perspectiva } \\
\text { dos profissionais de } \\
\text { saúde }^{(2)} \text {. }\end{array}$ & $\begin{array}{l}\text { Conhecer a cultura de } \\
\text { segurança do paciente } \\
\text { em unidades de terapia } \\
\text { intensiva. }\end{array}$ & $\begin{array}{l}\text { Entrevistas } \\
\text { semiestruturadas }\end{array}$ & $\begin{array}{l}\text { Emergiram duas categorias: } \\
\text { Percepção sobre o erro e } \\
\text { Gestão do erro. }\end{array}$ \\
\hline
\end{tabular}

Fonte: Elaboração própria.

\section{Discussão}

As informações extraídas das produções foram agrupadas de acordo com as similaridades encontradas em três categorias: análise de instrumentos para avaliação da cultura de segurança do paciente, composta pelos artigos número 4, 5, e 20; fortalezas e fragilidades da cultura de segurança do paciente em terapia intensiva, composta pelos artigos número 3, 5, 7, 10, 13, 14, 15, $16,18,19$, e 22; cultura de segurança do paciente em terapia intensiva e fatores associados, composta pelos artigos número 1, 2, 4, 6, 8, 9, 11, 12, $17,19,19$ e 21.

\section{Análise de instrumentos para avaliação da cultura de segurança do paciente}

As publicações analisadas utilizaram O HSOPSC, O SAQ e entrevistas semiestruturas para executar suas avaliações. O HSOPSC é composto por 42 itens, distribuídos em 12 dimensões.
Considera-se áreas de força para a segurança do paciente aquelas dimensões em que mais de 75\% dos entrevistados forneceram respostas positivas para a segurança do paciente. Do mesmo modo, considera-se uma cultura de segurança do paciente local positiva, quando se encontra um nível geral de cultura de segurança do paciente acima de $75 \%{ }^{(23)}$.

O SAQ é composto por 41 itens, distribuídos em 6 domínios. A pontuação do instrumento varia de 0 a 100 e os valores são considerados positivos, quando a pontuação total é maior ou igual a $75^{(32)}$.

Ambos são bastante utilizados mundialmente e foram validados para a realidade brasileira ${ }^{(8)}$.

Três trabalhos dedicaram-se à exploração e comparação dos instrumentos de mensuração da cultura de segurança do paciente, que são compostos por dimensões ou domínios que captam o comportamento dos profissionais sobre aspectos fundamentais da segurança do paciente. 
O SAQ foi apresentado como uma ferramenta útil para avaliações de desempenho comparativo entre UTINs, em pesquisa norte-americana, fornecendo um parâmetro para avaliar necessidade e oportunidades de iniciativas de melhoria da qualidade $^{(30)}$.

Do mesmo modo, com o intuito de comparar o desempenho de UTINs em clima de segurança e clima de trabalho em equipe entre o SAQ e o HSOPSC, foi constatado que tais aspectos dos dois instrumentos correlacionaram-se fortemente. Para cada escala, o uso dos dois questionários resultou em desempenho semelhante numa mesma UTI ${ }^{(15)}$.

Entretanto, ao comparar o resultado de várias UTIs, seus desempenhos diferiram fortemente. Por exemplo, uma UTI classificada em $23^{\circ}$ no HSOPSC, teria ficado em $3^{\circ}$ no SAQ. Diante disso, embora tenham sido encontradas áreas de concordância entre os instrumentos, devido a tais distinções recomenda-se cautela na comparação e transição de uso entre os instrumentos ${ }^{(15)}$.

Estudo brasileiro também analisou a relação entre o SAQ e o HSOPSC. Escore geral do HSOPSC e domínio "clima de segurança" do SAQ, escore geral do HSOPSC e escore geral do SAQ, e dimensão "retroalimentação das informações e comunicação sobre os erros" do HSOPSC e escores geral do SAQ, foram as maiores correlações encontradas com significância estatística $(\mathrm{p}<0,000)$, porém com valores moderados de correlação. Tais correlações moderadas foram relacionadas ao fato de que os itens da maioria das dimensões do HSOPSC abordam o erro diretamente, diferente da escala $\mathrm{SAQ}^{(8)}$.

Os resultados das duas últimas produções não demonstram que os instrumentos sejam equivalentes e o quantitativo reduzido de publicações que fornecem informações sobre a comparação dos instrumentos indicam a necessidade de outras investigações.

\section{Fortalezas e fragilidades da cultura de segurança do paciente em terapia intensiva}

A avaliação de cultura de segurança do paciente pode ser utilizada, dentre outras coisas, para avaliar o status atual da cultura de segurança do paciente e identificar pontos fortes e áreas para melhoria da cultura de segurança.

Das 11 produções que relataram os resultados descritivos das avaliações de cultura de segurança, 7 utilizaram o HSOPSC. Destas, nenhuma foi considerada como uma cultura de segurança do paciente local positiva ${ }^{(8,17,23-24,28-29)}$.

No que diz respeito às dimensões, a maioria das pesquisas não apresentou nenhuma dimensão com percentual de respostas positivas acima de 75\%, com exceção de 3, que foram desenvolvidas no Brasil, no Irã, e na Noruega. A primeira com apenas uma dimensão com tal característica e as demais com duas dimensões consideradas de força para a segurança ${ }^{(8,17,23-24,28-29)}$.

Das quatro publicações que utilizaram o SAQ como instrumento de avaliação, nenhuma obteve pontuação geral superior a 75 , e duas demonstraram somente um domínio com mais de 75 pontos $^{(8,14,20,26)}$. Estes resultados foram semelhantes aos encontrados com o HSOPSC, O que sugere a complexidade da concretização da cultura de segurança do paciente em ambientes de cuidados críticos.

As avaliações oriundas do HSOPSC demonstraram três dimensões com pontuações mais altas na maioria dos estudos. "Trabalho em equipe no âmbito das unidades", "Expectativas e ações de promoção de segurança dos supervisores e gerentes" e "Aprendizado organizacional e melhoria contínua" (8,17,23-24,28-29).

Quanto às dimensões com menor percentual de respostas positivas, estiveram presentes na maioria das avaliações "Respostas não punitivas aos erros" e "Apoio da gestão hospitalar para a segurança do paciente",(8,17,23-24,28-29).

O domínio do SAQ "Satisfação no trabalho" foi o que obteve pontuação mais alta na maioria das investigações que utilizaram este instrumento; o domínio "Percepção da gestão da unidade e do hospital" obteve as menores pontuações ${ }^{(8,14,20,26)}$.

Destaca-se o fato de que as avaliações que aplicaram o HSOPSC consideraram que os gerentes possuem uma postura mais proativa em relação à segurança do paciente, do que as avaliações que empregaram o SAQ, já que, neste último, os itens que se referem à aprovação das 
ações da gerência quanto às questões de segurança atingiram pontuações inferiores.

Dentre os trabalhos que utilizaram o HSOPSC, um teve como objetivo sistematizar as recomendações dos profissionais de enfermagem acerca da segurança do paciente em duas UTIs. A maioria das recomendações encontradas não estiveram associadas com as dimensões que obtiveram as piores avaliações da maioria dos estudos. Houve maior número de recomendações para as dimensões "Aprendizado organizacional e melhoria contínua", "Profissionais" e "Percepção geral de segurança do paciente" ${ }^{(25)}$.

Em investigação que aplicou entrevistas semiestruturadas, emergiram duas categorias: "Percepção sobre o erro" e "Gestão do erro". Nestas os profissionais reconheceram a possibilidade do erro na assistência à saúde, atribuindo sua ocorrência tanto às falhas individuais quanto às falhas do sistema. Assim, defendiam a cultura justa em detrimento da cultura punitiva ${ }^{(2)}$.

Este resultado também difere das avaliações oriundas do HSOPSC, em que os profissionais temiam a cultura punitiva e acreditavam que essa ainda permeava a gestão dos problemas relacionados à segurança do paciente.

\section{Cultura de segurança do paciente em terapia intensiva e fatores associados}

O exame das publicações permitiu conhecer os determinantes da cultura de segurança do paciente, que apontam para possíveis intervenções de melhoria necessárias para a promoção de um ambiente mais seguro.

Foi identificado que a Síndrome de Burnout está associada às percepções mais baixas da cultura de segurança do paciente em estudo que utilizou o $\mathrm{SAQ}^{(12)}$. Do mesmo modo, pesquisa conduzida pelo HSOPSC identificou associação entre uma cultura de segurança positiva e a ausência de Burnout. Esta associação deve-se ao fato de que essa síndrome diminui o comprometimento com o trabalho e, consequentemente, a percepção para a segurança do paciente torna-se menos sensível ${ }^{(28)}$. Destarte, medidas preventivas dessa condição nos profissionais de saúde podem ajudar a desenvolver uma cultura de segurança mais fortalecida.

Outras características dos profissionais também estiveram associadas à cultura de segurança do paciente, a exemplo de tempo de trabalho no hospital, tempo de trabalho na unidade, categoria profissional e o sexo. Indivíduos com menos de um ano de trabalho no hospital e na unidade, profissionais médicos e homens tendiam a ter um percentual maior de respostas positivas nas avaliações ${ }^{(15,22)}$. Além disso, o porte da UTI foi identificado como um fator determinante dos escores de cultura de segurança, uma vez que UTIs menores foram relacionadas a melhores resultados nas investigações ${ }^{(15)}$.

Corrobora este entendimento, pesquisa que aplicou o HSOPSC antes e após a reestruturação de unidades que passaram por fusão de diferentes UTIs e notou que a reestruturação foi negativamente associada com a mudança na cultura de segurança, em particular as dimensões relacionadas à unidade ${ }^{(13)}$.

Outro fator determinante foram as rondas de segurança, em que o feedback proveniente dessas foi associado a melhores resultados de cultura de segurança. As rondas de segurança criam espaços para o diálogo entre os líderes e a equipe de linha de frente, para identificar riscos e coletar informações, a fim de melhorar os processos em torno da segurança do paciente ${ }^{(18)}$.

A realização de treinamentos e capacitações relacionados à segurança do paciente também foi associada a melhores resultados nas avaliações de cultura de segurança tanto naquelas mensuradas pelo SAQ quanto com o HSOPSC ${ }^{(27,29,31)}$. No entanto, destaca-se o fato de que as dimensões "respostas não punitiva aos erros", em um estudo ${ }^{(31)}$, e "frequência de eventos relatados", em dois estudos ${ }^{(29,31)}$, não melhoraram significativamente com essa intervenção, sugerindo que a notificação de problemas de segurança e a maneira como os funcionários sentem-se com relação aos seus erros são ainda mais complexos.

A cultura de segurança do paciente também esteve associada a desfechos clínicos importantes. Pesquisa que utilizou o SAQ constatou que, para cada $10 \%$ de queda na porcentagem de pontuações positivas da UTI para percepções 
de gestão, o aumento da chance de morte foi de 1,24 ( $\mathrm{p}=0,005)$. Além deste achado, para cada 10\% de redução no percentual da pontuação positiva do clima de segurança da UTI, o tempo de permanência aumentou 15\% $(\mathrm{p}=0,03)^{(19)}$.

Outro desfecho associado à cultura de segurança foram as infecções relacionadas ao uso de cateteres. Investigação americana, que aplicou o HSOPSC no início e após a implementação de medidas para reduzir tais infecções, não encontrou associação entre os resultados da avaliação e as taxas de infecção de corrente sanguínea associada a cateter venoso central e infecção do trato urinário associada cateter vesical ${ }^{(16)}$.

Em contrapartida, pesquisa que também aplicou o HSOPSC e investigou a relação entre perfis climáticos de segurança do paciente na UTI e taxas de infecção de corrente sanguínea associada à cateter venoso central encontrou diferentes resultados. A investigação demonstrou que UTIs com climas conflitantes (liderança local e equipe de linha de frente não percebiam o compromisso da gestão organizacional e de outras unidades com a segurança do paciente) tiveram um risco significativamente maior desse tipo de infecção em comparação com as UTIs que apresentavam clima de liderança generativa (altos níveis de suporte da gestão hospitalar à segurança do paciente e colaboração entre unidades foram percebidos como uma prioridade) ${ }^{(21)}$.

Portanto, fica evidente que modificações na cultura de segurança são capazes de reduzir os riscos de eventos indesejáveis, gerando melhores resultados e desfechos na assistência à saúde.

O fato de terem sido utilizados apenas três portais de busca de publicações constitui-se em limitação do estudo, uma vez que outras investigações sobre a temática podem não ter sido incluídas nesta revisão.

\section{Conclusão}

A efetivação da cultura de segurança é essencial no contexto dos cuidados críticos e avaliações frequentes são indispensáveis para sua solidificação. Para isto, estão disponíveis instrumentos que possibilitam a identificação de áreas com aspectos positivos e áreas que necessitam de melhorias.
Das pesquisas que demonstraram os resultados descritivos das avaliações, nenhuma apresentou uma cultura de segurança do paciente positiva. No máximo duas dimensões foram consideradas áreas de força para a segurança. Isto demonstra o quanto é difícil construir uma cultura de segurança local em unidades de terapia intensiva, e que não são poucos os esforços necessários para tal objetivo. Tal fato desperta a necessidade de os serviços de saúde realizarem avaliações de cultura de segurança, a fim de conhecer suas fragilidades e traçar intervenções efetivas. Ademais, incita a refletir sobre a premência da abordagem da segurança do paciente nos currículos das instituições de ensino, formando profissionais preparados para o desenvolvimento de culturas de segurança positivas.

A presente investigação revelou como fatores associados à cultura de segurança, aspectos como síndrome de Burnout, tempo de trabalho no hospital, tempo de trabalho na unidade, categoria profissional, sexo, porte da UTI, reestruturação das unidades, feedback das rondas de segurança e treinamentos e capacitações. Além disso, resultados das avaliações de cultura de segurança estiveram associados a desfechos clínicos importantes, como mortalidade, tempo de permanência e infecções relacionadas ao uso de cateteres.

É importante que mais estudos sejam realizados para conhecer outros determinantes, bem como para aprofundar o conhecimento dos já conhecidos, com vistas à concretização da cultura de segurança do paciente, promovendo cuidados seguros e de qualidade.

\section{Colaborações:}

1 - concepção, projeto, análise e interpretação dos dados: Nathália Dantas Farias Kruschewsky e Kátia Santana Freitas;

2 - redação do artigo e revisão crítica relevante do conteúdo intelectual: Nathália Dantas Farias Kruschewsky, Kátia Santana Freitas e Aloísio Machado da Silva Filho;

3 - aprovação final da versão a ser publicada: Nathália Dantas Farias Kruschewsky, Kátia Santana Freitas e Aloísio Machado da Silva Filho. 


\section{Referências}

1. Bezerra ALQ. A Segurança do Paciente e a Enfermagem. Rev Nursing [Internet]. 2018 [cited 2019 Jul 20];21(239):2091. Disponível em: http://www.revistanursing.com.br/revistas/239Abril2018/editorial.pdf

2. Souza CS, Tomaschewski-Barlem JG, Rocha LP, Barlem ELD, Silva TL, Neutzling BRS. Cultura de segurança em unidades de terapia intensiva: perspectiva dos profissionais de saúde. Rev Gaucha Enferm. 2019;40(esp):e20180294. DOI: https://doi.org/10.1590/1983-1447.2019.20180294

3. World Health Organization. More Than Words: Conceptual Framework for the International Classification for Patient Safety [Internet]. Geneva; 2009 [cited 2019 Jul 20]. Available from: https:// www.who.int/patientsafety/taxonomy/icps_full_ report.pdf

4. World Health Organization. Human Factors in Patient Safety: Review of Topics and Tools [Internet]. Geneva; 2009 [cited 2019 Jul 20]. Available from: https://www.who.int/patientsafety/ research/methods_measures/human_factors/ human_factors_review.pdf

5. Brasil. Ministério da Saúde. Portaria no 529, de $1^{\circ}$ de abril de 2013. Institui o Programa Nacional de Segurança do Paciente (PNSP) [Internet]. Brasília (DF); 2013 [cited 2019 Jul 20]. Available from: http://bvsms.saude.gov.br/bvs/saudelegis/ gm/2013/prt0529_01_04_2013.html

6. Sorra J, Gray L, Streagle S, Rockville W, Famolaro T, Yount N, et al. AHRQ Hospital Survey on Patient Safety Culture: User's Guide [Internet]. Rockville; 2018 [cited 2019 Jul 20]. Available from: https://www.ahrq.gov/sites/ default/files/wysiwyg/professionals/qualitypatient-safety/patientsafetyculture/hospital/ userguide/hospcult.pdf

7. Minuzzi AP, Salum NC, Locks MOH. Avaliação da Cultura de Segurança do Paciente em Terapia Intensiva na Perspectiva da Equipe de Saúde. Texto contextoenferm. 2016;25(2):e20180294.DOI:http:// dx.doi.org/10.1590/1983-1447.2019.20180294

8. Santiago THR, Turrini RNT. Cultura e clima organizacional para segurança do paciente em Unidades de Terapia Intensiva. Rev Esc Enferm USP. 2015;49(esp):123-30. DOI: https://doi. org/10.1590/S0080-623420150000700018.

9. Brasil. Ministério da Saúde. Resolução no 7, de 24 de fevereiro de 2010. Dispõe sobre os requisitos mínimos para funcionamento de Unidades de Terapia Intensiva e dá outras providências [Internet]. Brasília (DF); 2010 [cited 2019 Jul 20]. Available from: http://bvsms.saude.gov.br/bvs/ saudelegis/anvisa/2010/res0007_24_02_2010.html

10. Brasil. Agência Nacional de Vigilância Sanitária. Relatórios dos Estados - Eventos Adversos [Internet]. Brasília (DF); 2019 [cited 2019 Jul 20]. Available from: https://www20.anvisa.gov.br/ segurancadopaciente/index.php/publicacoes/ category/relatorios-dos-estados

11. Whittemore R, Knaf $\mathrm{K}$. The integrative review: updated methodology. J Adv Nurs. 2005;52(5):54653. DOI: $10.1111 /$ j.1365-2648.2005.03621.x.

12. Profit J, Sharek PJ, Amspoker AB, Kowalkowski MA, Nisbet CC, Thomas EJ, et al. Burnout in the NICU setting and its relation to safety culture. BMJ Qual Saf. 2014;23(10):806-13. DOI: 10.1136/ bmjqs-2014-002831

13. Vifladt A, Simonsen BO, Lydersen S, Farup PG. Changes in patient safety culture after restructuring of intensive care units: Two cross-sectional studies. Intensive Crit Care Nurs. 2016;32:58-65. DOI: 10.1016/j.iccn.2015.06.004

14. Chaboyer W, Chamberlain D, Hewson-Conroy K, Grealy B, Elderkin T, Brittin M, et al. CNE article: safety culture in Australian intensive care units: establishing a baseline for quality improvement. Am J Crit Care. 2013;22(2):93-102. DOI: 10.4037/ ajcc2013722

15. Profit J, Lee HC, Sharek PJ, Kan P, Nisbet CC, Thomas EJ, et al. Comparing NICU teamwork and safety climate across two commonly used survey instruments. BMJ Qual Saf. 2016;25(12):954-61. DOI: 10.1136/bmjqs-2014-003924

16. Meddings J, Reichert H, Greene MT, Safdar N, Kerin SL, Olmsted RN, et al. Evaluation of the association between Hospital Survey on Patient Safety Culture (HSOPS) measures and catheterassociated infections: results of two national collaboratives. BMJ Qual Saf. 2017;26(3):226-35. DOI: http://dx.doi.org/10.1136/bmjqs2015-005012

17. Tomazoni A, Rocha PK, Kusahara DM, Souza AIJ, Macedo TR. Avaliação da cultura de segurança do paciente em terapia intensiva neonatal. Texto contexto enferm. 2015;24(1):161-9. DOI: https:// doi.org/10.1590/0104-07072015000490014

18. Sexton JB, Sharek PJ, Thomas EJ, Gould JB, Nisbet CC, Amspoker AB, et al. Exposure to Leadership WalkRounds in neonatal intensive care units is associated with a better patient safety culture and less caregiver burnout. BMJ 
Qual Saf. 2014;23(10):814-22. DOI: 10.1136/ bmjqs-2013-002042

19. Huang DT, Clermont G, Kong L, Weissfeld LA, Sexton JB, Rowan KM, et al. Intensive care unit safety culture and outcomes: a US multicenter study. Int J Qual Health Care. 2010;22(3):151-61. DOI: 10.1093/intqhe/mzq017

20. Jochen L, Etchegaray J, Petersen LA, Sexton JB, Hysong SJ, Mei M, et al. Neonatal intensive care unit safety culture varies widely. Arch Dis Child Fetal Neonatal Ed. 2012;97(2):120-6. DOI: 10.1136/ archdischild-2011-300635

21. Weaver SJ, Weeks K, Pham JC, Pronovost PJ. On the CUSP: Stop BSI: evaluating the relationship between central line-associated bloodstream infection rate and patient safety climate profile. Am J Infect Control. 2014;42(10):S203-8. DOI: 10.1016/j.ajic.2014.05.020

22. Tomazoni A, Rocha PK, Souza S, Anders JC, Malfussi HFC. Cultura de segurança do paciente em unidades de terapia intensiva neonatal: perspectivas da equipe de enfermagem e médica. Rev lat-am enferm. 2014;22(5):755-63. DOI: 10.1590/0104-1169.3624.2477

23. Mello JF, Barbosa SFF. Cultura de segurança do paciente em unidade de terapia intensiva: perspectiva da equipe de enfermagem. Rev eletrônica enferm. 2017;19:1-12. DOI: https://doi. org/10.5216/ree.v19.38760

24. Farzi S, Moladoost A, Bahrami M, Farzi S, Etminani R. Patient Safety Culture in Intensive Care Units from the Perspective of Nurses: A Cross-Sectional Study. Iran J Nurs Midwifery Res. 2017;22(5):372-6. DOI: 10.4103/ijnmr.IJNMR_150_16

25. Mello JF, Barbosa SFF. Cultura de segurança do paciente em terapia intensiva: recomendações da enfermagem. Texto contexto enferm. 2013;22(4):1124-33. DOI: https://doi.org/10.1590/ S0104-07072013000400031

26. Reis FFP, Oliveira KF, Luiz RB, Barichello E, Cruz LF, Barbosa MH. Cultura de segurança em unidades de terapia intensiva. Rev enferm atenção saúde. 2017;6(2):34-48. DOI: https://doi. org/10.18554/reas.v6i2.1991

27. Meurling L, Hedman L, Sandahl C, Felländer-Tsai L, Wallin C-J. Systematic simulation-based team training in a Swedish intensive care unit: a diverse response among critical care professions. BMJ Qual Saf. 2013;22(6):485-94. DOI: 10.1136/bmjqs-2012000994

28. Vifladt A, Simonsen BO, Lydersen S, Farup PG. The association between patient safety culture and burnout and sense of coherence: A cross-sectional study in restructured and not restructured intensive care units. Intensive Crit Care Nurs [Internet]. 2016 [cited 2019 Jul 10];36:2634. DOI: 10.1016/j.iccn.2016.03.004

29. Ling L, Gomersall CD, Samy W, Joynt GM, Leung $\mathrm{CCH}$, Wong WT, et al. The Effect of a Freely Available Flipped Classroom Course on Health Care Worker Patient Safety Culture: A Prospective Controlled Study. J Med Internet Res. 2016;18(7):e180. DOI: 10.2196/jmir.5378

30. Profit J, Etchegaray J, Petersen LA, Sexton JB, Hysong SJ, Mei M, et al. The Safety Attitudes Questionnaire as a tool for benchmarking safety culture in the NICU. Arch Dis Child Fetal Neonatal Ed. 2012;97(2):127-32. DOI: 10.1136/ archdischild-2011-300612

31. Amiri M, Khademian Z, Nikandish R. The effect of nurse empowerment educational program on patient safety culture: a randomized controlled trial. BMC Med Educ. 2018;18(1):1-8. DOI: https:// doi.org/10.1186/s12909-018-1255-6

32. Carvalho REFL, Cassiani SHB. Questionário Atitudes de Segurança: adaptação transcultural do Safety Attitudes Questionnaire - Short Form 2006 para o Brasil. Rev lat-am enferm. 2012;20(3):575-82. DOI: https://doi.org/10.1590/ S0104-11692012000300020

Recebido: 5 de junho de 2020 Aprovado: 13 de agosto de 2020 Publicado: 24 de novembro de 2020

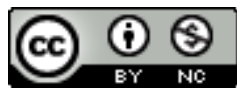

A Revista Baiana de Enfermagem utiliza a Licença Creative Commons - Atribuição-NãoComercial 4.0 Internacional. https://creativecommons.org/licenses/by-nc/4.0/ Este artigo é de acesso aberto distribuído sob os termos da Licença Creative Commons (CC BY-NC). Esta licença permite que outros remixem, adaptem e criem a partir do seu trabalho para fins não comerciais. Embora os novos trabalhos tenham de lhe atribuir o devido crédito e não possam ser usados para fins comerciais, os usuários não têm de licenciar esses trabalhos derivados sob os mesmos termos. 